\title{
突発性難聴に対する高気圧酸素併用療法の比較
}

\author{
鈴木 秀明・宇高 敦・橋田 光一・森 貴稔 \\ 平木 信明・若杉 哲郎・永谷 群司

\section{Hyperbaric Oxygen in Combination with Other Therapies for Idiopathic Sudden Sensorineural Hearing Loss}

\author{
Hideaki Suzuki, Tsuyoshi Udaka, Koichi Hashida, Takanori Mori, \\ Nobuaki Hiraki, Tetsuro Wakasugi and Gunji Nagatani \\ (University of Occupational and Environmental Health, School of Medicine)
}

\begin{abstract}
Hyperbaric oxygen (HBO) therapy combined with steroid administration is an effective treatment for idiopathic sudden sensorineural hearing loss (ISSNHL), but is sometimes unfeasible for patients with underlying diseases, particularly for those with steroid-intolerance. We conducted a controlled retrospective analysis of patients with ISSNHL who received HBO in combination with stellate ganglion block (SGB), prostaglandin $(\mathrm{PG}) \mathrm{E}_{1}$, or steroid therapy in order to identify possible alternative regimens.

Three hundred and six consecutive patients with ISSNHL (average hearing levels of 5 frequencies $(250-4000 \mathrm{~Hz}) \geqq 40 \mathrm{~dB}$; time from the onset of hearing loss to the start of treatment $\leqq 30$ days) were enrolled. One hundred and ten, 95, and 101 patients underwent SGB + HBO (SGB group), PGE $_{1}+\mathrm{HBO}$ (PG group), and steroid $+\mathrm{HBO}$ therapy (steroid group), respectively. Hearing recovery was evaluated by grade assessment, by hearing gain, and by hearing improvement rate compared to the unaffected contralateral ear.

The overall hearing outcome did not differ among the three groups. In patients with initial hearing levels $<80 \mathrm{~dB}$, the PG group tended to show a higher cure rate, recovery rate, hearing gain, and hearing improvement rate compared to those of the other groups. In contrast, in patients with initial hearing levels $\geqq 80 \mathrm{~dB}$, the SGB group tended to show a higher recovery rate, hearing gain, and hearing improvement rate compared to those of the other groups, and the hearing improvement rate was significantly higher in the SGB group than in the PG group (53.0 $05.0 \%$ vs. $35.3 \pm 6.8 \% ; \mathrm{p}<0.05$ ).

We concluded that both $\mathrm{SGB}+\mathrm{HBO}$ and $\mathrm{PGE}_{1}+\mathrm{HBO}$ are promising alternative regimens for ISS$\mathrm{NHL}$, and that $\mathrm{SGB}+\mathrm{HBO}$ and $\mathrm{PGE}_{1}+\mathrm{HBO}$ are recommended for patients with initial hearing levels $\geqq$ $80 \mathrm{~dB}$ and $<80 \mathrm{~dB}$, respectively.
\end{abstract}

Key words : hyperbaric oxygen, idiopathic sudden sensorineural hearing loss, steroid, stellate ganglion block, prostaglandin $\mathrm{E}_{1}$

はじめに

突発性難聴は特発性の急性感音難聴であり，その病態 に関しては循環障害説, ウイルス感染説, 内耳空破裂説, 自己免疫説などが提唱されている ${ }^{1)}$. 原因が不明である
ことから, ステロイド, 抗凝固・血栓溶解薬, 脱線維素 原療法, プロスタグランジン (PG) 製剤, インターフェ ロン，高気圧酸素療法（HBO），星状神経節ブロック （SGB）などを主体とした種々の治療法が行われている 
が，決め手となる治療法は確立されておううす，いくつか を組み合わせた治療法の優劣についても議論が続いてい る. 加えて，無治療例の中にも自然治癒が少なからず認 められる2)ことが，本疾患の治療をさらに混乱させる要 因となっている．当科では突発性難聴に対し，1989 年ま ではステロイド単独投与を行い，1990 年以降は HBO を 基本としてこれに $\mathrm{SGB}, \mathrm{PGE}_{1}$ ，またはステロイドを併用 した治療を行ってきた。 そしてこれまでに，ステロイド + HBO 治療群の有効性がステロイド単独投与群に比し て有意に優れていることを報告した ${ }^{3)}$ ，今回われわれは $\mathrm{HBO}$ を含んだ併用療法群間の有効性の違いについて検 討した.

\section{対象と方法}

当科を受診した突発性難聴患者のうち，重症な基礎疾 患を有する場合や治療拒否例を除いた全例に対し, 入院 のうえ, 下記の治療法を施行した。 このうち 5 周波数 （250〜 $4000 \mathrm{~Hz}$ ) の平均聴力レベルが $40 \mathrm{~dB}$ 以上（Grade 2 以上）で発症から治療開始までの期間が 30 日以内の 306 症例 306 耳について検討を行った.

全例に対し HBO を行い，これに加えて $1990 \sim 1996$ 年は SGB を $(\mathrm{SGB}$ 群; $\mathrm{n}=110), 1997 \sim 2001$ 年は $\mathrm{PGE}_{1}$ を（PG 群；n=95), 2002 年以降はステロイドを（Steroid 群; $\mathrm{n}=101$ ) 併用した. $\mathrm{HBO}$ は $100 \% \mathrm{O}_{2}$ 吸入下に 2.5 気 圧，60 分を 1 日 1 回 $\times$ 週 5 回 $\times 2$ 週間（計 10 回），平日 午後に施行した. $\mathrm{SGB}$ と $\mathrm{PGE}_{1}$ 投与 $(20 \sim 40 \mu \mathrm{g} / 100 \mathrm{ml}$

表 1 ステロイド投与のプロトコール

\begin{tabular}{ccc}
\hline \hline 日 & & \\
\hline 1 & コハク酸ヒドロコーチゾン & $400 \mathrm{mg}$ 点滴静注 \\
2 & コハク酸ヒドロコーチゾン & $400 \mathrm{mg}$ 点滴静注 \\
3 & コハク酸ヒドロコーチゾン & $400 \mathrm{mg}$ 点滴静注 \\
4 & コハク酸ヒドロコーチゾン & $200 \mathrm{mg}$ 点滴静注 \\
5 & コハク酸ヒドロコーチゾン & $200 \mathrm{mg}$ 点滴静注 \\
6 & コハク酸ヒドロコーチゾン & $200 \mathrm{mg}$ 点滴静注 \\
7 & コハク酸ヒドロコーチゾン & $100 \mathrm{mg}$ 点滴静注 \\
8 & コハク酸ヒドロコーチゾン & $100 \mathrm{mg}$ 点滴静注 \\
9 & コハク酸ヒドロコーチゾン & $100 \mathrm{mg}$ 点滴静注 \\
10 & プレドニゾロン & $10 \mathrm{mg}$ 経口 \\
11 & プレドニゾロン & $10 \mathrm{mg}$ 経ロ \\
12 & プレドニゾロン & $10 \mathrm{mg}$ 経ロ \\
13 & プレドニゾロン & $5 \mathrm{mg}$ 経ロ \\
14 & プレドニゾロン & $5 \mathrm{mg}$ 経ロ
\end{tabular}

表 2 判定基準 (厚生省特定疾患急性高度難聴調査研究班報告書 ${ }^{4}$ )

治癒： 5 周波数 $(250 \sim 4000 \mathrm{~Hz})$ すべての聴カレベルが $20 \mathrm{~dB}$ 以内に回復, または健側聴力レベルと同程度まで改善 したもの.

著明回復: 5 周波数平均聴力レベルの改善が $30 \mathrm{~dB}$ 以上のもの.

回復: 5 周波数平均聴力レベルの改善が $10 \mathrm{~dB}$ 以上 $30 \mathrm{~dB}$ 未満 のもの.

不変（悪化を含む）：5 周波数平均聴力レベルの改善が $10 \mathrm{~dB}$ 未満のもの.

生理食塩水, 点滴静注）は HBO 施行に合わせ，その直 前に行った. ステロイド投与は表 1 に示したように，コ 八ク酸ヒドロコーチゾンを $400 \mathrm{mg} /$ 日より 2 週間かけて 漸減投与した. 9 日目までのコハク酸ヒドロコーチゾン は午前中に，10〜14 日目のプレドニゾロンは朝食後に 1 日 1 回投与した.

治療開始後 1 力月の時点の聴力を治療後聴力とし, 治 療成績については厚生省特定疾患急性高度難聴調查研究 班報告書の判定基準4) に従い 5 周波数（250～4000 Hz） の平均聴力レベルに基づいて段階評価した（表 2)。治癒 の割合を治癒率，著明回復以上の割合を有効率とし，初 診時聴力レベルと治療後聴カレベルの差を聴力利得とし た。 さらに健側聴力を基準にした聴力改善の割合を聴力 改善率として次の式により算出した ${ }^{5}$.

聴力改善率 $=$ (初診時患側聴力レベルー治療後患側聴 カレベル) / (初診時患側聴力レベル

一健側聴力レベル） $\times 100 （ \%)$

データは，平均士標準誤差として表記した。平均值の 差は両側 Student $\mathrm{t}$ 検定で，比率の差は $\chi^{2}$ 検定にて統計 学的解析を行い, $\mathrm{p}<0.05$ をむって有意差ありとした.

\section{結 果}

各群のプロフィールを表 3 に示す．年齢とめまいの合 併率は SGB 群と Steroid 群との間で有意差があった。男 女差と初診時聴力は PG 群と Steroid 群の間で, 治療開始 までの期間は SGB 群と PG 群の間でそれぞれ有意差が認 められた，全体の治療成績を表 4 亿示す，治癒率，有効 率，聴力改善率，聴力利得いずれについても 3 群間で差 がなかった. 次に，初診時聴力が $80 \mathrm{~dB}$ 未満と $80 \mathrm{~dB}$ 以 上の症例に分けて検討した結果を表 5 に示す. $80 \mathrm{~dB}$ 未 満の場合には，PG 群が他の 2 群に比べて治癒率，有効 率，聴力改善率，聴力利得いずれも，有意ではないが高 
表 3 各群のプロフィール

\begin{tabular}{|c|c|c|c|c|}
\hline & SGB 群 & PG 群 & Steroid 群 & Statistics \\
\hline 症例数 & 110 & 95 & 101 & \\
\hline 年齢（歳） & $48.6 \pm 1.8^{\mathrm{a}}$ & $51.6 \pm 1.7$ & $54.1 \pm 1.6^{\mathrm{a}}$ & ${ }^{\mathrm{a}} \mathrm{p}<0.05$ \\
\hline 男: 女 & $62: 48$ & $59: 36^{\mathrm{b}}$ & $46: 55^{\mathrm{b}}$ & ${ }^{\mathrm{b}} \mathrm{p}<0.05$ \\
\hline めまい合併 & $11 / 110(10.0 \%)^{c}$ & $12 / 95(12.6 \%)$ & $23 / 101(22.5 \%)^{c}$ & ${ }^{c} \mathrm{p}<0.02$ \\
\hline 初診時聴力（dB） & $79.1 \pm 1.8$ & $83.5 \pm 1.9^{\mathrm{d}}$ & $74.7 \pm 1.9^{\mathrm{d}}$ & ${ }^{d} \mathrm{p}<0.001$ \\
\hline 治療開始前期間（日） & $7.8 \pm 0.5^{\mathrm{e}}$ & $5.2 \pm 0.5^{\mathrm{e}}$ & $6.4 \pm 0.5$ & ${ }^{e} \mathrm{p}<0.001$ \\
\hline
\end{tabular}

表 4 全体の治療成績

\begin{tabular}{lcccc}
\hline \hline & SGB 群 & PG 群 & Steroid 群 & Statistics \\
\hline 治癒率 & $23 / 110(20.9 \%)$ & $27 / 95(28.4 \%)$ & $29 / 101(28.7 \%)$ & NS \\
有効率 & $61 / 110(55.5 \%)$ & $52 / 95(54.7 \%)$ & $54 / 101(53.5 \%)$ & NS \\
聴力利得 $(\mathrm{dB})$ & $31.8 \pm 2.1$ & $31.2 \pm 2.2$ & $27.2 \pm 2.3$ & $\mathrm{NS}$ \\
聴力改善率 & $57.3 \pm 3.9 \%$ & $48.4 \pm 5.1 \%$ & $53.9 \pm 4.2 \%$ & $\mathrm{NS}$
\end{tabular}

NS ; not significant

表 5 初診時聴力別の治療成績

\begin{tabular}{|c|c|c|c|c|}
\hline & SGB 群 & PG 群 & Steroid 群 & Statistics \\
\hline \multicolumn{5}{|l|}{ 初診時聴力 $<80 \mathrm{~dB}$} \\
\hline 症例数 & 52 & 38 & 63 & \\
\hline 治癒率 & $15 / 52(28.8 \%)$ & $19 / 38(50.0 \%)$ & $21 / 63(33.3 \%)$ & NS \\
\hline 有効率 & $26 / 52(50.0 \%)$ & $23 / 38 \quad(60.5 \%)$ & $34 / 63(54.0 \%)$ & NS \\
\hline 聴力利得 (dB) & $25.7 \pm 2.5$ & $32.2 \pm 3.1$ & $24.9 \pm 2.7$ & NS \\
\hline 聴力改善率 & $62.0 \pm 6.2 \%$ & $68.1 \pm 6.6 \%$ & $59.5 \pm 5.5 \%$ & NS \\
\hline \multicolumn{5}{|l|}{ 初診時聴力 $\geqq 80 \mathrm{~dB}$} \\
\hline 症例数 & 58 & 57 & 38 & \\
\hline 治癒率 & $8 / 58(13.8 \%)$ & $8 / 57(14.0 \%)$ & $8 / 38 \quad(21.1 \%)$ & NS \\
\hline 有効率 & $35 / 58(60.3 \%)$ & $29 / 57 \quad(50.9 \%)$ & $20 / 38 \quad(52.6 \%)$ & NS \\
\hline 聴力利得（dB） & $37.2 \pm 3.3$ & $30.8 \pm 3.1$ & $30.9 \pm 4.2$ & NS \\
\hline 聴力改善率 & 53. $0 \pm 5.0 \% *$ & $35.3 \pm 6.8 \% *$ & $44.5 \pm 6.2 \%$ & $* \mathrm{p}<0.05$ \\
\hline
\end{tabular}

NS ; not significant

い傾向がみられた。 これに対し $80 \mathrm{~dB}$ 以上の症例では, SGB 群が他の 2 群に比べて有効率, 聴力改善率, 聴力利得 が高い傾向にあり, 聴力改善率は PG 群に比べて SGB 群 が有意に高かった（35. $3 \pm 6.8 \%$ vs. $53.0 \pm 5.0 \%)$.

\section{考察}

突発性難聴の治療にはステロイドがもっとも広く用い られているが，その科学的根拠は 1980 年に Wilson ら ${ }^{6)}$ が報告した無作為化二重盲検不活性プラセボ比較試験に
基づいている. 突発性難聴に対する治療法で，このよう な厳密な水準により有効性が立証されたものは他にな く，ステロイド治療の重要性については論を俟たない。 しかし, その有効率は $60 \sim 70 \%$ 止まりであることや, 基 礎疾患の併存のため投与困難な場合があることなどか ら，依然として他の治療法が模索されているのが現状で ある.われわれの施設でも 1989 年まではステロイド単独 投与を行っていたが, その後治療成績のさらなる向上を 目指して HBO を導入した。 
突発性難聴の病態は循環障害であるという説に基づい て，1970 年代後半から HBO がその治療に使われはじめ $た^{788)}$. Nakashima $ら^{99}$, Horn $ら^{10)}$ は突発性難聴に対する HBO を報告したが,これらの研究では対照群が設定され ていない. Aslan ら ${ }^{11)}$, Racic ら ${ }^{12)}$, Narozny $~^{{ }^{13)}}$ は後ろ 向き比較解析によって, さらに Fattori ら ${ }^{14)}$, Topuz ら ${ }^{15)}$ は無作為化比較試験によって, HBO の有効性を検証し た.

$\mathrm{HBO}$ と同様に SGB も循環障害の改善を目的とした治 療法である. Haug ら ${ }^{16)}$ は SGB を受けた突発性難聴患者 の 70\%が回復したのに対し, 他療法では $15 ２ 0 \%$ の患 者しか回復しなかったと述べた.さらに Goto ら ${ }^{8)}$ は, $\mathrm{SGB}$ と $\mathrm{HBO}$ の併用によって通常の薬物療法よりも良好 な治療成績が得られたことを示し，とくに初診時聴力が $80 \mathrm{~dB}$ 以上の患者で有効性が高かったことを報告した.

$\mathrm{PGE}_{1}$ は強力な血管拡張作用を持つエイコサノイドで あり, この他にも細胞保護作用, 抗炎症作用, 線溶系促 進作用, 血小板凝集抑制作用などを有し, 循環障害を病 態とする諸疾患に優れた効果を発揮する。 しかし, 突発 性難聴に対する $\mathrm{PGE}_{1}$ の臨床的効果は明らかではない. Nakashima ら ${ }^{17)}$ やSuzuki ら ${ }^{1819)}$ が行った後ろ向き比較解 析や Ogawa ら ${ }^{20)}$ による無作為化二重盲検比較試験で は, 対照群に優る $\mathrm{PGE}_{1}$ の有効性は示されなかった. Ahn $ら^{21)}$ は, 遊離型 $\mathrm{PGE}_{1}$ よりも生物学的半減期が長く, よ り高い効果が期待できる lipo- $\mathrm{PGE}_{1}$ とメチルプレドニゾ ロンとの併用投与を行ったが，メチルプレドニゾロン単 独投与群との間に有効性の差を見いだすことができな かった.

これに対して動物実験では， $\mathrm{PGE}_{1}$ の類似体である $\mathrm{PGE}_{2}$ の椎骨動脈内投与や鼓室内投与は蝸牛血流量を増 加させることが知られている2223)．さらにラットを使っ た蝸牛微小血管塞栓モデルでは, $\mathrm{PGE}_{1}$ の静注が蝸牛神 経の複合活動電位の低下を防ぐ効果を発揮することが報 告されている24)，突発性難聴に対する $\mathrm{PGE}_{1}$ の臨床的有 効性が確認できない理由は不明であるが，投与法，投与 量，併用療法などを調整することにより効果を引き出す ことができる可能性は残されているだろう.

われわれの最近の検討ではステロイド+ HBO はステ ロイド単独投与よりも優れており ${ }^{3)}$, 現在, 当施設にお ける標準レジメとしているが, 重症の糖尿病, 消化性潰 瘍，肝炎，緑内障，感染症などの基礎疾患を有する症例 には適応しにくいという欠点がある. 今回の検討で, 全
体の治療成績からみて，ステロイド+HBO の代替レジメ として $\mathrm{SGB}+\mathrm{HBO}$ と $\mathrm{PGE}_{1}+\mathrm{HBO}$ はともに有望である と考えられた。 そして, 初診時聴力別の治療成績からみ て初診時聴力が $80 \mathrm{~dB}$ 以上の場合は $\mathrm{SGB}+\mathrm{HBO}$ を, $80 \mathrm{~dB}$ 未満の場合には $\mathrm{PGE}_{1}+\mathrm{HBO}$ を適応するのがよいと考え られた。

\section{まとめ}

1. 突発性難聴に対する $\mathrm{HBO}$ と他療法 $\left(\mathrm{SGB}, \mathrm{PGE}_{1}\right.$, ステロイド）との併用群間の有効性の違いについて検討 した.

2. 全体の治療成績は 3 群間で差がなかった。

3. 初診時聴力が $80 \mathrm{~dB}$ 未満の症例では, $\mathrm{PG}$ 群が他の 2 群に比べて治療成績が良い傾向であったのに対し, $80 \mathrm{~dB}$ 以上の症例では，SGB 群が他の 2 群に比べて有効 率，聴力利得，聴力改善率が高い傾向にあり，聴力改善 率は PG 群に比べて SGB 群が有意に高かった。

4. Steroid＋HBO の代替レジメとして SGB + HBO と $\mathrm{PGE}_{1}+\mathrm{HBO}$ はともに有望であり，初診時聴力に応じて $\mathrm{SGB}+\mathrm{HBO}$ と $\mathrm{PGE}_{1}+\mathrm{HBO}$ を使い分けるのがよいと考えら れた。

\section{参考文献}

1) Eisenman DJ and Arts HA : Effectiveness of treatment for sudden sensorineural hearing loss. Arch Otolaryngol Head Neck Surg $126: 1161 \sim 1164,2000$.

2) Mattox DE and Simmons FB : Natural history of sudden sensorineural hearing loss. Ann Otol Rhinol Laryngol $86: 463 \sim$ 480, 1977.

3) Fujimura T, Suzuki H, Shiomori T, et al. : Hyperbaric oxygen and steroid therapy for idiopathic sudden sensorineural hearing loss. Eur Arch Otorhinolaryngol $264: 861 \sim 866,2007$.

4）野村恭也：総括研究報告書. 厚生省特定疾患急性高度難聴 調查研究班昭和 59 年度研究業績報告書 : $1 \sim 3,1985$.

5) Suzuki H, Furukawa M, Kumagai M, et al. : Defibrinogenation therapy for idiopathic sudden sensorineural hearing loss in comparison with high-dose steroid therapy. Acta Otolaryngol $123: 46 \sim 50,2003$.

6) Wilson WR, Byl FM and Laird N : The efficacy of steroids in the treatment of idiopathic sudden hearing loss. A double-blind clinical study. Arch Otolaryngol $106: 772 \sim 776,1980$.

7) Vincey $P$ : Application and use of hyperbaric oxygenation in ENT. Rev Laryngol Otol Rhinol (Bord) 99:619 634, 1978.

8) Goto F, Fujita T, Kitani $Y$, et al. : Hyperbaric oxygen and stellate ganglion blocks for idiopathic sudden hearing loss. Acta 
Otolaryngol $88: 335 \sim 342,1979$.

9) Nakashima $T$, Fukuta $S$ and Yanagita $N$ : Hyperbaric oxygen therapy for sudden deafness. Adv Otorhinolaryngol $54: 100 \sim$ 109, 1998.

10) Horn $\mathrm{CE}$, Himel $\mathrm{HN}$ and Selesnick $\mathrm{SH}$ : Hyperbaric oxygen therapy for sudden sensorineural hearing loss: a prospective trial of patients failing steroid and antiviral treatment. Otol Neurotol $26: 882 \sim 889,2005$.

11) Aslan I, Oysu C, Veyseller B, et al. : Does the addition of hyperbaric oxygen therapy to the conventional treatment modalities influence the outcome of sudden deafness? Otolaryngol Head Neck Surg $126: 121 \sim 126,2002$.

12) Racic G, Maslovara $S$, Roje $Z$, et al. : Hyperbaric oxygen in the treatment of sudden hearing loss. ORL J Otorhinolaryngol Relat Spec $65: 317 \sim 320,2003$.

13) Narozny W, Sicko $Z$, Przewozny T, et al. : Usefulness of high doses of glucocorticoids and hyperbaric oxygen therapy in sudden sensorineural hearing loss treatment. Otol Neurotol 25 : $916 \sim 923,2004$.

14) Fattori B, Berrettini $S$, Casani A, et al. : Sudden hypoacusis treated with hyperbaric oxygen therapy: a controlled study. Ear Nose Throat J $80: 655 \sim 660,2001$.

15) Topuz E, Yigit O, Cinar U, et al. : Should hyperbaric oxygen be added to treatment in idiopathic sudden sensorineural hearing loss? Eur Arch Otorhinolaryngol $261: 393 \sim$ 396, 2004.

16) Haug O, Draper WL and Haug SA : Stellate ganglion blocks for idiopathic sensorineural hearing loss. Arch Otolaryngol $102: 5$ $\sim 8,1976$.

17) Nakashima $T$, Kuno $K$ and Yanagita $N$ : Evaluation of prostaglandin $E_{1}$ therapy for sudden deafness. Laryngoscope $99: 542$
〜 546, 1989.

18) Suzuki H, Fujimura $T$, Ikeda $K$, et al. : Prostaglandin $E_{1}$ in combination with hyperbaric oxygen therapy for idiopathic sudden sensorineural hearing loss. Acta Otolaryngol 128:61 $65,2008$.

19) Suzuki H, Fujimura T, Shiomori $T$, et al. : Prostaglandin $E_{1}$ versus steroid in combination with hyperbaric oxygen therapy for idiopathic sudden sensorineural hearing loss. Auris Nasus Larynx $35: 192 \sim 197,2008$.

20) Ogawa $K$, Takei $S$, Inoue $Y$, et al. : Effect of prostaglandin $E_{1}$ on idiopathic sudden sensorineural hearing loss: a doubleblinded clinical study. Otol Neurotol $23: 665 \sim 668,2002$.

21) Ahn JH, Kim MR and Kim HC : Therapeutic effect of lipoprostaglandin $\mathrm{E}_{1}$ on sudden hearing loss. Am J Otolaryngol 26:245 $\sim 248,2005$.

22) Umemura K, Takiguchi $Y$, Nakashima M, et al. : Effect of arachidonic acid on the inner ear blood flow measured with a laser Doppler flowmeter. Ann Otol Rhinol Laryngol 99:491 495, 1990.

23) Rhee CK, Park YS, Jung TT, et al. : Effects of leukotrienes and prostaglandins on cochlear blood flow in the chinchilla. Eur Arch Otorhinolaryngol $256: 479 \sim 483,1999$.

24) Umemura $K$ and Nakashima $M$ : Effect of prostaglandin $E_{1}$ on the rat inner ear microvascular thrombosis. Gen Pharmacol $28: 221 \sim 224,1997$.

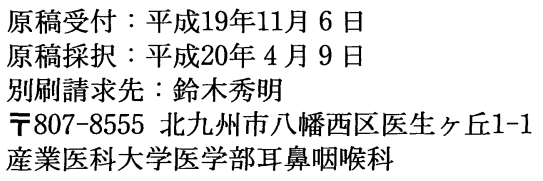

